\title{
Article
}

\section{Selective transport of amino acids across a cation-exchange membrane via the specific reaction with metal ions fixed as counter ions in the membrane.}

\author{
Manabu IGAWA* and Hiroshi SUZUKI \\ Faculty of Engineering, Kanagawa University,Rokkakubashi, Kanagawa-kau, Yokohama, 221-8686 Japan
}

(Manuscript submitted, February 13, 2003; accepted, March 10, 2003)

\begin{abstract}
Amino acids can be selectively transported across a cation-exchange membrane via the specific reaction with heavy metal ions fixed as counter ions in the membrane. The selectivity depends on the complex formation constants of the amino acids with the metal ions, although the transport of amino acids was also facilitated by the proton fixed on the cation-exchange membrane. The transport rate was much dependent not only on the stability constants but also on the stiring intensity at the surface of the membrane in the source phase solution. The transport mechanism and the permeation characteristics of amino acids were studied on the equilibrium theory.
\end{abstract}

\section{Introduction}

Mutual separation of solutes is an important subject in membrane technology and there have been many reports on the separation with membranes. The liquid membrane is an effective separation method but the organic solvents and the carriers, which are expensive and toxic in most cases, are dissolved from the membrane into the aqueous solution. When one uses ion-exchange membranes, it is possible to separate solutes without organic solvents. Some reagent fixed on the membrane has the potential to be a selective separation method of some solute via the specific reaction of the solute with the reagent Although there have been many reports on the selective transport of metal ions across ion-exchange membrane, $[1,2]$ organic solutes can be also separated with ion-exchange membranes. It has been reported that the transport of olefins was facilitated through the cation-exchange membrane fixed with silver ion[3,4] and that of aldehydes through the anion-xchange membrane fixed with hydrogensulfite ion [5] Facilitated transport of carbohydrates were also reported across ion-exchange membranes via the reaction of borate ion [6] or hydroxide ion [7] fixed on the anion-exchange membrane.

We have tried to permeate amino acids selectively across a cation-exchange membrane via the specific reaction with metal ions fixed on the membrane. Amino acids were selectively transported efficiently across the cation-exchange membrane in the system via the complexation reaction with the metal ion. In this paper, we will report the permeation characteristics of the amino acids in the system and the transport mechanism.

\section{Experimental}

Transport experiment was carried out with a flow type cell shown in Fig. 1 at room temperature. The cell was composed of two compartments, that is, source phase and receiving phase compartments, which were partitioned by a cation-exchange membrane (Asahi Glass Co. Ltd., Selemion CMV). Each solution was circulated from each reservoir to the compartment by a tubing pump at a rate of $30 \mathrm{~mL} \mathrm{~min}^{-1}$. The membrane area was $10.5 \mathrm{~cm}^{2}$ and the thickness of each compartment was $\mathrm{ca} .1 \mathrm{~mm}$. A spacer of nylon screen with the thickness of $1.16 \mathrm{~mm}$ was inserted in each compartment of the cell. In the transport experiment, aliquots of the solution of each phase were collected in a definite interval. The ion flux was calculated from the linear region of the 
concentration change of the receiving phase with time. The membrane was pretreated as follows before the transport experiment to be changed to some metal-ion type membrane. The cation-exchange membrane was immersed into $100 \mathrm{~mL}$ aqueous solution of $0.1 \mathrm{~mol} \mathrm{~L}^{-1}$ $\mathrm{HCl}, \mathrm{NaCl}, \mathrm{CuCl}_{2}$ or $\mathrm{FeCl}_{3}$ for $1 \mathrm{hr}$ to be changed to $\mathrm{H}^{+}$, $\mathrm{Na}^{+}, \mathrm{Cu}^{2+}$, or $\mathrm{Fe}^{3+}$ type. The immersion was repeated three times in each fresh solution, and the membrane was rinsed with pure water.

The adsorption amount of amino acids to the membrane was measured as follows to clarify the interaction of amino acids with the metal ion. A membrane of some metal ion type $(3 \mathrm{~cm} \times 3 \mathrm{~cm})$ was immersed in $50 \mathrm{~mL}$ amino acid solution in a centrifugal precipitation tube with a stopper. The solution in the tube was shaken by a shaker for $3 \mathrm{hrs}$ to adsorb amino acids to the membrane. Amino acids were determined before and after the adsorption experiment to obtain the adsorption amount.

The amino acids were determined by a total organic carbon analyzer (Shimadzu, TOC-5000). Metal ions were determined by an atomic adsorption spectrophotometer (Varian, AA-1275), and the solution $\mathrm{pH}$ was measured by a pH meter(Toa HM-60S).

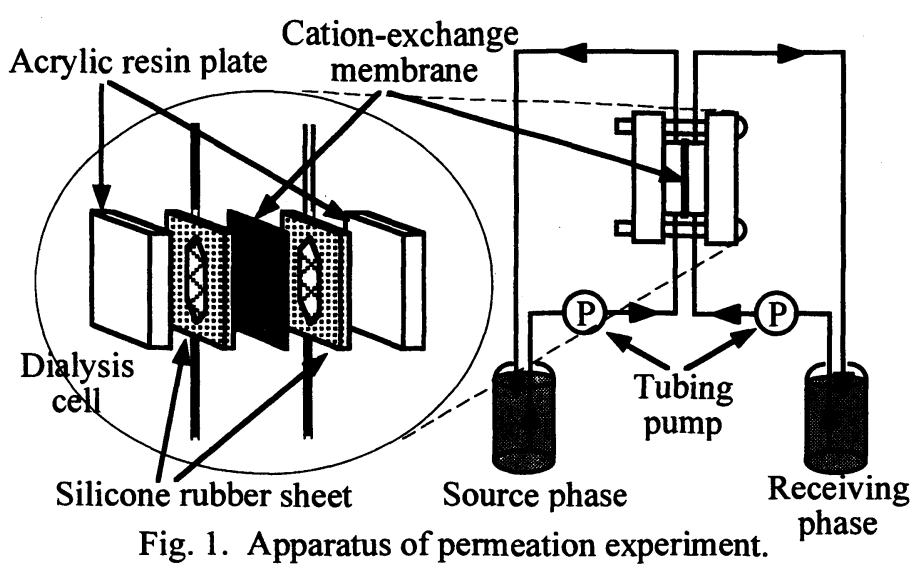

\section{Results and Discussion}

Figure 2 shows the adsorption behaviors of glycine to $\mathrm{H}^{+}, \mathrm{Na}^{+}, \mathrm{Cu}^{2+}$, and $\mathrm{Fe}^{3+}$ type membranes. The order of the adsorption amount was $\mathrm{H}^{+}$type $>\mathrm{Fe}^{3+}$

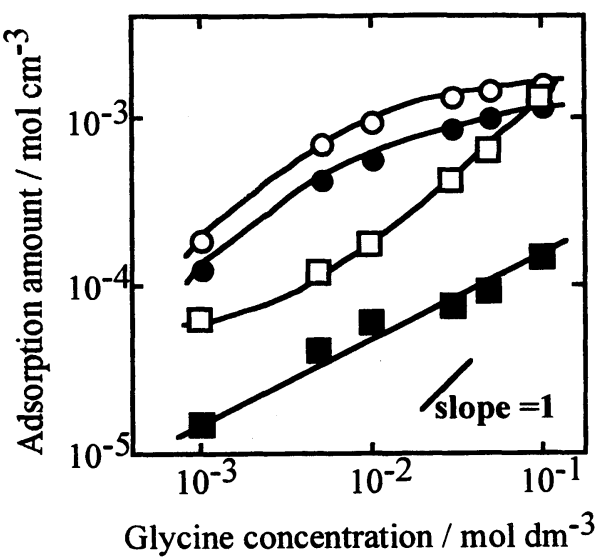

Fig. 2. Glycine adsorption amount vs. concentration for each type cationexchange membrane. $\mathrm{H}^{+}$type (O); $\mathrm{Cu}^{2+}$

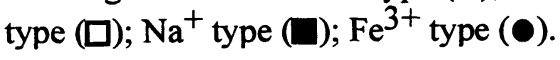
type $>\mathrm{Cu}^{2+}$ type $>\mathrm{Na}^{+}$type, and the adsorption amount increased with the concentration. The stability constants of $1: 1$ complex of glycine with metal ions are reported as follows; $\mathrm{Fe}^{3+}, 10^{10.0} ; \mathrm{Cu}^{2+}, 10^{8.60}[8]$. Alkaline metal ions such as $\mathrm{Na}^{+}$hardly complex with most of chelating reagents and the order is reasonable. The adsorption amount is related to the solution concentration as follows, when a glycine (Gly) is bonded to an ion fixed in the membrane (subscript, $\mathrm{m}$ ).

$$
\begin{aligned}
& \mathrm{Gly}+\mathrm{H}_{\mathrm{m}}^{+} \rightleftarrows \mathrm{Gly}_{\mathrm{m}}^{+} \\
& \mathrm{K}_{1}=\left[\mathrm{Gly}^{+}\right]_{\mathrm{m}} /\left([\mathrm{Gly}] \cdot\left[\mathrm{H}^{+}\right]_{\mathrm{m}}\right) \\
& \mathrm{Gly}+\mathrm{M}^{\mathrm{n}+}{ }_{\mathrm{m}} \rightleftarrows \mathrm{GlyM}{ }^{(\mathrm{n}-1){ }^{+}}{ }_{\mathrm{m}}+\mathrm{H}_{\mathrm{m}}^{+} \\
& \mathrm{K}_{2}=\left(\left[\mathrm{GlyM}^{(\mathrm{n}-1)+}\right]_{\mathrm{m}} \cdot\left[\mathrm{H}^{+}\right]_{\mathrm{m}}\right) /\left([\mathrm{Gly}] \cdot\left[\mathrm{M}^{\mathrm{n}+}\right]_{\mathrm{m}}\right)
\end{aligned}
$$

When the glycine in the membrane is determined, it is difficult to distinguish between the glycine-metal ion complex and the glycine in the membrane. Therefore, the total concentration of glycine in the membrane was defined as follows.

$$
\begin{aligned}
& {\left[\mathrm{Gly}_{\mathrm{m}}{ }^{\mathrm{T}}=\left[\mathrm{GlyM}^{(\mathrm{n}-1)+}\right]_{\mathrm{m}}+[\mathrm{Gly}]_{\mathrm{m}}\right.} \\
& {\left[\mathrm{GlyM}^{(\mathrm{n}-1)+}\right]_{\mathrm{m}}=[\mathrm{Gly}]_{\mathrm{m}}{ }^{\mathrm{T}} \cdot \mathrm{a}} \\
& {[\mathrm{Gly}]_{\mathrm{m}}=\left[\mathrm{Gly}_{\mathrm{m}}\right]^{\mathrm{T}} \cdot(1-\mathrm{a})}
\end{aligned}
$$

From these equations and under the condition of $\left[\mathrm{Gly}_{m}{ }^{\mathrm{T}}<<\mathrm{C}_{e x}\right.$, which is the ion-exchange capacity, the following equations can be obtained because $\left[\mathrm{M}^{\mathrm{n}+} I_{\mathrm{m}}\right.$ is approximately equal to $C_{e} / n$.

$$
\begin{aligned}
& \left([\mathrm{Gly}]_{\mathrm{m}}^{\mathrm{T}} / \mathrm{a} \cdot[\mathrm{Gly}]_{\mathrm{m}}^{\mathrm{T}} /(1-\mathrm{a})\right)=\mathrm{K}_{1} \mathrm{~K}_{2}[\mathrm{Gly}]^{2}\left[\mathrm{M}^{\mathrm{n}+}\right]_{\mathrm{m}}=\mathrm{K}_{1} \mathrm{~K}_{2}[\mathrm{Gly}]^{2} \mathrm{C}_{\mathrm{\alpha}} / \mathrm{n} \\
& \log [\mathrm{Gly}]_{\mathrm{m}}^{\mathrm{T}}=0.5 \log \mathrm{K}_{1} \mathrm{~K}_{2}+0.5 \log \{\mathrm{a}(1-\mathrm{a})\}+\log [\mathrm{Gly}]+0.5 \log \left(\mathrm{C}_{\mathrm{e}} / \mathrm{n}\right)
\end{aligned}
$$


When a is constant, there is a linear relationship between [Gly $]_{m}{ }^{\mathrm{T}}$ and [Gly]. In $\mathrm{H}^{+}$type membrane, glycine is bonded not to metal ions but to proton in the membrane, and Eq. 9 is simplified as follows.

$$
\log [\mathrm{Gly}]_{\mathrm{m}}{ }^{\mathrm{T}}=\log \mathrm{K}_{1}+\log [\mathrm{Gly}]+\log \mathrm{C}_{\mathrm{ex}}
$$

There are concentration regions with the slope of one in Fig. 2 for $\mathrm{H}^{+}, \mathrm{Fe}^{3+}$, and $\mathrm{Cu}^{2+}$ type membranes as estimated by these equations. Therefore, the reaction of amino acids with proton or metal ions in the membrane described above is reasonable.

Figure 3 shows the glycine flux vs. source phase concentration. The flux increases with the concentration and the order of the flux was $\mathrm{H}^{+}$type $>$ $\mathrm{Cu}^{2+}$ type $>\mathrm{Na}^{+}$type $>\mathrm{Fe}^{3+}$ type. The adsorption amount was large for $\mathrm{Fe}^{3+}$ type membrane, but the flux was small. However for $\mathrm{Cu}^{2+}$ type and $\mathrm{Na}^{+}$ type membranes, copper ions and sodium ions were desorbed from each membrane to both source phase and receiving phase solutions, and therefore, $\mathrm{Fe}^{3+}$ type membrane was used further in our study of selective permeation of amino acids. The slope in Fig. 3 was about one for $\mathrm{H}^{+}$type membrane, while that of $\mathrm{Fe}^{3+}$ was much lower. When glycine was transferred from the membrane to the receiving phase, reverse reaction of Eq. 1 easily occurs but that of Eq. 3 needs $\mathrm{H}_{\mathrm{m}}^{+}$. When the concentration of $\mathrm{H}_{\mathrm{m}}^{+}$decreased, the stripping rate decreased at the membrane surface to the receiving phase. Therefore, the flux may decrease with the concentration because of the increase of $\left[\mathrm{M}^{\mathrm{n}+} \mathrm{l}_{\mathrm{m}}\right.$ and the decrease of $\left[\mathrm{H}^{+}\right]_{\mathrm{m}}$.

Figure 4 shows the selective permeabilities of amino acids. The flux increased with the distribution coefficient, which depends on the complexation constant, but there is a maximum value. In the carbohydrates permeation across borate ion type anion-exchange membrane, the solutes with high complexation coefficient is difficult to be transported.[6] In this case, amino acids may complex rapidly with the metal ion fixed on the membrane but the complex should be decomposed to be transferred to the next site or released to the receiving phase. The amino acids with large stability constants of complexation have a small decomposition rate constants, which may depress the transport rate.

Figure 5 shows the effect of flow rate in the source phase on the flux of glycine. There were some effects, which means that the diffusion in the source phase sublayer at the membrane surface is the rate limiting step. The flux, $J$, can be described by using a permeation constant, $P$, in the sublayer.

$$
J=P\left([\mathrm{Gly}]_{\mathrm{b}}-[\mathrm{Gly}]_{\mathrm{s}}\right)
$$

The subscripts $b$ and $s$ mean the bulk and the membrane surface in the source phase, respectively. The uptake reaction to the membrane can be described as follows if the reverse reaction can be ignored.

$$
J=k_{1}[\mathrm{Gly}]_{s} \mathrm{C}_{\mathrm{m}}
$$

The symbol $\mathrm{C}$ means the reactant concentration at the membrane surface,

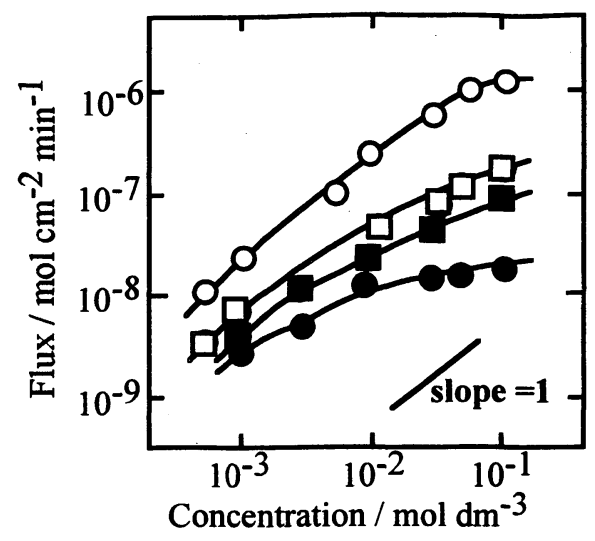

Fig. 3. Glycine flux vs. concentration for each type cation-exchange membrane. $\mathrm{H}^{+}$

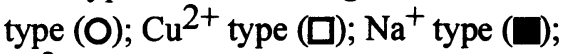
$\mathrm{Fe}^{3+}$ type (O).

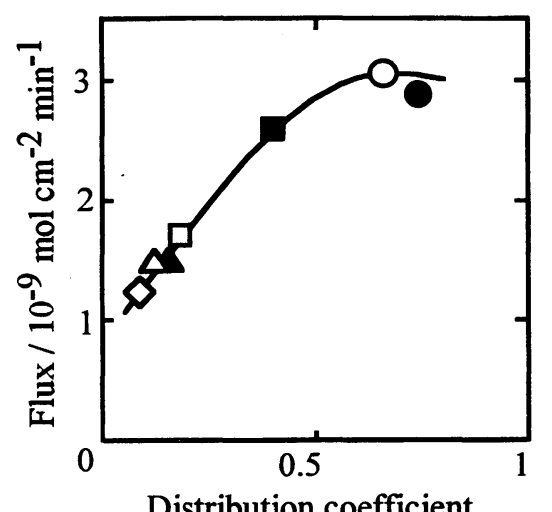

Fig. 4. Flux vs. distribution coefficient for $\mathrm{Fe}^{3+}$ type cation-exchange membrane. DL-glutamic acid $(\boldsymbol{\nabla})$; L-lysine $(\boldsymbol{\Delta})$; Lmethionine (A); L-histidine ( $\square$ ); Lalanine (ם); B-alanine (O); glycine (O).

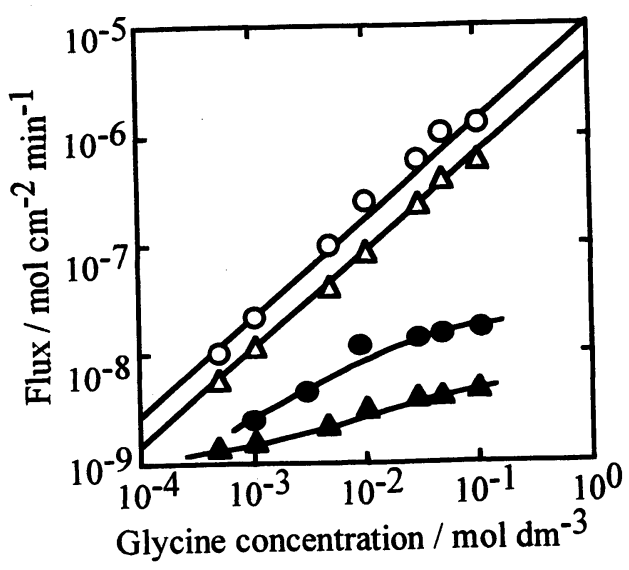

Fig. 5. Effect of flow rate on the flux on glycine across $\mathrm{H}^{+}$type $(0, \Delta)$ and $\mathrm{Fe}^{3+}$ type $(\bullet, \Delta)$ membrane. Flow rate, $5 \mathrm{~cm}^{3}$ $\min ^{-1}(\Delta, \Delta)$ or $30 \mathrm{~cm}^{3} \mathrm{~min}^{-1}(0, \bullet)$. 
that is, $\left[\mathrm{Fe}^{3+} l_{m}\right.$ or $\left[\mathrm{H}^{+}\right]_{m}$ in the case of Fig. 5. From these two equations, Eq. 13 can be obtained.

$$
J=P[\mathrm{Gly}] /\left\{1+P /\left(k_{1} \mathrm{C}_{\mathrm{m}}\right)\right\}
$$

If the product, $k_{1} \mathrm{C}_{\mathrm{m}}$ is constant, the ratio, $J /[\mathrm{Gly}]_{\mathrm{b}}$ depends on only $P$. The concentration, $\mathrm{C}_{\mathrm{m}}$ is $\mathrm{C}_{\mathrm{ex}} / \mathrm{n}$, except for high glycine concentration in the source phase, the two lines should be parallel. The lines of $\mathrm{H}^{+}$type membrane are parallel but those of $\mathrm{Fe}^{3+}$ type are not. In both cases, the pumping rate in the receiving phase did not affect the fluxes. Therefore, glycine transport was dominated by the transport rate in the source phase sublayer at the membrane surface and the uptake rate to the membrane in $\mathrm{H}^{+}$ type membrane. On the other hand, glycine transport was dominated not only these two steps but also other step in $\mathrm{Fe}^{3+}$ type membrane. The other rate limiting step may be the stripping process at the receiving phase.

\section{Acknowledgements}

We appreciate the support by High-Tech Research Project from The Ministry of Education, Culture, Sports, Science and Technology.

\section{References}

1) D. Langevin, M. Metayer, M. Hankaoui, and B. Pollet, "Ton Exchange For Industry" Ellis Horwood, Chichester(1988) p. 566.

2) M. Igawa, Y. Narita, and H. Okochi, Bull. Chem. Soc., Jpn., 75, 2269 (2002).

3) C. A. Koval and T. Spontarell, J. Am. Chem. Soc., 110, 293 (1988).

4) P. Klausener and D. Woremann, J. Membr. Sci, 168, 27 (2000).

5) M. Igawa, Y. Fukushi, T. Hayashita, and M. R. Hoffmann, I\&EC Research, 29, 857 (1990).

6) M. Igawa, T. Sekimoto, and H. Okochi, J. Mebr. Sci., 98, 177 (1995).

7) Y. Shigemasa, S. Okamoto, H. Sashiwa, and H. Saimoto, Chem. Lett., 433 (1984).

8) “Lange's Handbook of Chemistry (12 ${ }^{\text {th }}$ Ed.)”, McGraw-Hill, Inc., New York (1979). 